\title{
Synthesis of a Random Block Copolymer Comprising Poly(styrene-ran-p-methoxystyrene) and Poly(styrene-ran-p-t-butoxystyrene) by 2,2,6,6-Tetramethylpiperidine-1-oxyl-mediated Living Radical Polymerization
}

\author{
Eri YoshIDA ${ }^{\dagger}$ and Yorihiro TAKIGUCHI
}

Department of Polymer Science and Engineering, Kyoto Institute of Technology,
Goshokaido-cho, Matsugasaki, Sakyo-ku, Kyoto 606-8585, Japan

(Received September 8, 1998)

\begin{abstract}
Radical polymerization of styrene (St) with $p$-methoxystyrene (MSt) and $p$ - $t$-butoxystyrene (BSt) was performed in the presence of 4-methoxy-2,2,6,6-tetramethylpiperidine-1-oxyl (MTEMPO), giving random copolymers with molecular weights controlled and with monomer unit ratios desired. The polymerization proceeded in accordance with a living mechanism, because molecular weight was in proportion to reciprocal of initial concentration of MTEMPO, and increased with conversion. Poly(St-ran-MSt) efficiently initiated the copolymerization of styrene with BSt, giving a block copolymer comprising poly(St-ran-MSt) and poly(St-ran-BSt), and vice versa. The $t$-butoxy groups of BSt units were selectively hydrolyzed to hydroxy groups, with formation of a random block copolymer including vinyl phenol units.
\end{abstract}

KEY WORDS Random Block Copolymer / 4-Methoxy-2,2,6,6-tetramethylpiperidine-1-oxyl / Living Radical Polymerization / Styrene / $p$-Methoxystyrene / $p$ - $t$-Butoxystyrene /

Living radical polymerization is superior in quantitatively preparing polymers because no side reactions of chain transfer and termination occur during polymerization. This polymerization has been used for creating a great variety of macromolecular architectures. These are telechelics, ${ }^{1-5}$ block and graft copolymers, ${ }^{6-7}$ cyclic polymers, ${ }^{8}$ and networks. ${ }^{9}$ Living radical polymerization has an advantage over living ionic polymerizations in that the simple procedure and the variety of monomers can be applied. The polymerization mediated by $2,2,6,6-$ tetramethylpiperidine-1-oxyl (TEMPO) has been the most extensively studied. There are a great number of publications on the kinetics and mechanisms of styrene polymerization mediated by TEMPO..$^{10-17}$ Publications on molecular design using the polymerization have been released. ${ }^{18-22}$ Well-defined random copolymers through living radical polymerization have another advantage over living ionic in that they are found in TEMPOmediated polymerization. Examples include copolymers of styrene with $p$-bromostyrene, ${ }^{23} p$-(chloromethyl)styrene, ${ }^{24}$ (meth)acrylates, ${ }^{25,26}$ and with 9-vinylcarbazole. $^{26}$ TEMPO-catalyzed polymerization produces block copolymers in great variety. These are not only simple block copolymers obtained by only method of TEMPO-mediated polymerization, ${ }^{27.28}$ but also block copolymers prepared by combining ionic polymerizations and TEMPO-catalyzed one. ${ }^{29-32}$ This polymerization has the potential to give block copolymers comprising random copolymer segments with molecular weight controlled and with unit ratio desired. These copolymers are expected to show properties based on the block and random copolymers. Fukuda et al. released a publication on the synthesis of a block copolymer consisting of polystyrene and poly(styrene-ran-acrylonitrile) by TEMPOcatalyzed polymerization. ${ }^{26}$ This polymer exhibits similar microphase segregation to that of poly(styrene-block-2vinylpyridine). A gradient copolymer ${ }^{33}$ and a block copolymer consisting of poly(styrene-ran-methyl metha-

\footnotetext{
+ To whom correspondence should be addressed
}

crylate) with different unit ratios ${ }^{34}$ were discovered through the living radical polymerization by transition metal complexes. We found a block copolymer comprising random copolymers of styrene with two different types of alkoxystyrenes by the radical polymerization using 4-methoxy-TEMPO. Living radical polymerization of alkoxystyrene by the $\mathrm{Cu}(\mathrm{I})$ complex is unsuccessful by reason that the oxidation of the growing radicals to carbocations occurs. ${ }^{35}$ TEMPO-mediated polymerization gives rise to well-defined random copolymers with alkoxystyrene because TEMPO has no ability to oxidize the growing radicals. The ideal copolymerization of styrene and alkoxystyrene should proceed in accordance with a living mechanism, since alkoxystyrenes have similar reactivities to that of styrene in radical polymerization. Some are easily hydrolyzed to vinyl phenol, with formation of a random block copolymer including vinyl phenol units. A publication has already been released on the synthesis of polymer containing vinyl phenol units through TEMPO-mediated polymerization of $p$ - $t$-butoxystyrene. ${ }^{36}$ This paper describes the synthesis of a random block copolymer of styrene with $p$-methoxystyrene and $p$ - $t$-butoxystyrene, and hydrolysis of the resulting copolymers.

\section{EXPERIMENTAL}

\section{Measurements}

Gel permeation chromatography (GPC) was performed with a Tosoh HLC-802A instrument equipped with a RI detector and with a Tosoh CP-8000 chromato processor. Two polystyrene gel columns of Tosoh TSK gel $\mathrm{G} 4000 \mathrm{H}_{8}$ and $\mathrm{G} 2000 \mathrm{H}_{8}$ was used with tetrahydrofuran (THF) as the eluent at $42{ }^{\circ} \mathrm{C}$. ${ }^{1} \mathrm{H}$ NMR spectra were obtained with a Bruker ARX-500 NMR spectrometer. Gas chromatography (GC) was performed with a Shimadzu GC-6A.

\section{Materials \\ 4-Methoxy-TEMPO (MTEMPO) was prepared as re-}




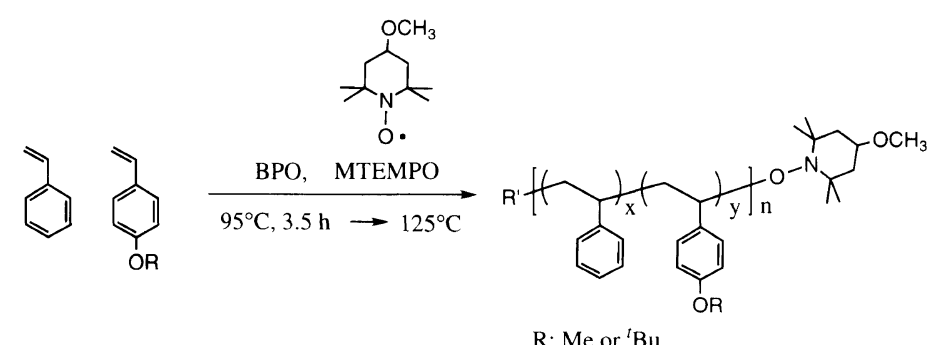

$\mathrm{R}$ ': benzoyl group or thermal initiator

Scheme 1.

${ }^{*} \mathrm{R}^{\prime}$ and MTEMPO moieties can connect to the units of styrene and alkoxystyrene.

Table I. Relationship between molecular weight and $[\mathrm{MTEMPO}]_{0}{ }^{a}$

\begin{tabular}{|c|c|c|c|c|c|c|}
\hline \multirow{2}{*}{ Comonomer } & \multirow{2}{*}{$\frac{[\mathrm{MTEMPO}]_{0}}{\times 10^{3} \mathrm{~mol} \mathrm{~L}^{-1}}$} & \multirow{2}{*}{$\frac{\text { Time }}{\mathrm{h}}$} & \multicolumn{2}{|c|}{ Conversion $\mathrm{b} / \%$} & \multirow{2}{*}{$M_{n}{ }^{\mathrm{c}}$} & \multirow{2}{*}{$M_{w} / M_{n}{ }^{\mathrm{c}}$} \\
\hline & & & St & Comonomer & & \\
\hline \multirow[t]{4}{*}{ MSt } & 96.8 & 65 & 92 & 94 & 26000 & 1.19 \\
\hline & 140 & 68 & 90 & 93 & 20000 & 1.23 \\
\hline & 204 & 68 & 91 & 91 & 14000 & 1.25 \\
\hline & 409 & 112 & 91 & 92 & 8700 & 1.27 \\
\hline \multirow[t]{4}{*}{ BSt } & 96.8 & 44 & 84 & 95 & 35000 & 1.17 \\
\hline & 140 & 44 & 82 & 92 & 25000 & 1.12 \\
\hline & 204 & 39 & 82 & 92 & 19000 & 1.12 \\
\hline & 409 & 68 & 80 & 92 & 11000 & 1.12 \\
\hline
\end{tabular}

${ }^{\mathrm{a}} \mathrm{MTEMPO} / \mathrm{BPO}=1.2 .{ }^{\mathrm{b}}$ Estimated by GC. ${ }^{\mathrm{c}}$ Estimated by GPC based on polystyrene standards.

ported previously. ${ }^{37}$ Commercial grade styrene $(\mathrm{St}), p$ methoxystyrene (MSt), and $p$ - $t$-butoxystyrene (BSt) were washed with aqueous alkaline solution and water, and distilled over calcium hydride. Benzoyl peroxide (BPO) was precipitated from chloroform into methanol and recrystallized at $0^{\circ} \mathrm{C}$. Toluene was purified by refluxing on sodium for several hours and distilled. Extrapure grade trifluoromethanesulfonic acid and trifluoroethanol were used without further purification.

\section{Radical Copolymerization of $S t$ and p-t-BSt: General} Procedure

St $(0.50 \mathrm{~mL}, 455 \mathrm{mg}, 4.36 \mathrm{mmol}), \quad$ BSt $(0.82 \mathrm{~mL}$, $769 \mathrm{mg}, 4.36 \mathrm{mmol})$, BPO (21 mg, $0.0866 \mathrm{mmol})$, and MTEMPO $(19 \mathrm{mg}, 0.102 \mathrm{mmol})$ were placed in an ampule. After degassing, the ampule was sealed in vacuo. Polymerization was carried out at first for $3.5 \mathrm{~h}$ at $95^{\circ} \mathrm{C}$, and continued for $39 \mathrm{~h}$ at $125^{\circ} \mathrm{C}$. It was terminated by cooling with liquid nitrogen. The product was dissolved in $10 \mathrm{~mL}$ dichloromethane, precipitated from dichloromethane into methanol, and finally dried in vacuo for several hours. The copolymer $(1.07 \mathrm{~g})$ was obtained. After the addition of toluene as internal standard, dichloromethane solution was subjected to GC to estimate the conversion of the monomers.

The copolymerization of St with MSt was carried out by the same procedure.

Random Block Copolymerization of St and p-MSt by Poly (St-ran-p-t-BSt)

St (1.25 mL, $1.14 \mathrm{~g}, 10.9 \mathrm{mmol})$, MSt $(1.45 \mathrm{~mL}, 1.46 \mathrm{~g}$, $10.9 \mathrm{mmol})$, and poly(St-ran-BSt) (St/BSt units $=0.495 /$ $0.505)(427 \mathrm{mg})$ were placed in an ampule. After degassing, the ampule was sealed in vacuo. Polymerization was carried out at $125^{\circ} \mathrm{C}$ for $12 \mathrm{~h}$ and terminated by cooling with liquid nitrogen. The product was dissolved in $20 \mathrm{~mL}$ dichloromethane, purified by repeating precipitations from dichloromethane into methanol, and freeze-dried with benzene. The copolymer $(2.08 \mathrm{~g})$ was obtained.

\section{Hydrolysis of a Random Block Copolymer of Poly(St-ran- p-BSt) and Poly(St-ran-p-MSt)}

A random block copolymer ( $\mathrm{St} / \mathrm{BSt}$ units $=0.495$ / 0.505 , St $/ \mathrm{MSt}$ units $=0.540 / 0.460$, poly $(\mathrm{St}-$ ran $-\mathrm{BSt}) /$ poly(St-ran-MSt) segments $=0.110 / 0.890)$ of $100 \mathrm{mg}$ was dissolved in $2 \mathrm{~mL}$ toluene, and the solution was placed in an ice bath at $-5^{\circ} \mathrm{C}$. Trifluoroethanol of 10 drops and trifluorosulfonic acid of 2 drops were added to the solution. The mixture was kept at $-5^{\circ} \mathrm{C}$ for $15 \mathrm{~min}$, and poured into $300 \mathrm{~mL}$ hexane to isolate the product. The product was dried in vacuo for several hours, and a polymer $(135 \mathrm{mg})$ was obtained.

\section{RESULTS AND DISCUSSION}

p-Alkoxystyrene shows similar reactivity to that of St in radical polymerization, and the products of $r_{1}$ and $r_{2}$ in copolymerization with $\mathrm{St}$ are almost equal to unity. ${ }^{38}$ Ideal copolymerizations should occur in accordance with a living mechanism by the presence of TEMPO. MTEMPO has the same reactivity as TEMPO in radical polymerization, and is useful in ${ }^{1} \mathrm{H}$ NMR analysis of polymers of styrene derivatives, since no signals of the methoxy protons overlap with other signals of the polymers. Copolymerization of St with MSt and with BSt was performed in bulk, in the presence of MTEMPO at $125^{\circ} \mathrm{C}$, after being held at $95^{\circ} \mathrm{C}$ for $3.5 \mathrm{~h}$ (Scheme 1). The results are listed in Table I. All conversions were high enough to compare molecular weights. 


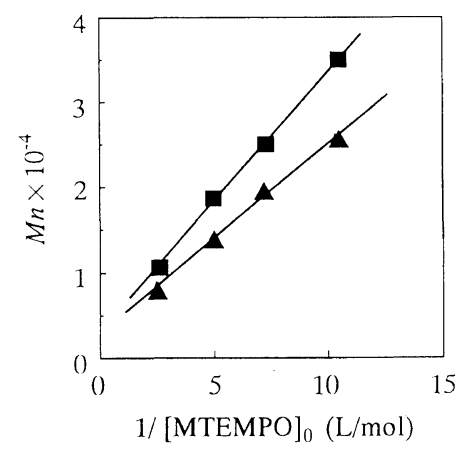

Figure 1. Plots of molecular weight versus reciprocal of [MTEMPO $]_{0}$ in copolymerization of St with MSt $(\boldsymbol{\Lambda})$ and with BSt ( $\mathbf{\square})$ by BPO and MTEMPO.

Table II. Copolymerization of St with MSt and with $\mathrm{BSt}^{\mathrm{a}}$

\begin{tabular}{|c|c|c|c|c|c|}
\hline \multirow{2}{*}{ Comonomer } & \multirow{2}{*}{$\frac{\text { Time }}{\mathrm{h}}$} & \multicolumn{2}{|c|}{ Conversion $\mathrm{b} / \%$} & \multirow{2}{*}{$M_{n}^{\mathrm{c}}$} & \multirow{2}{*}{$M_{w} / M_{n}^{\mathrm{c}}$} \\
\hline & & St & Comonomer & & \\
\hline \multirow[t]{4}{*}{ MSt } & 6 & 28 & 26 & 4400 & 1.33 \\
\hline & 12 & 48 & 50 & 8000 & 1.27 \\
\hline & 18 & 60 & 63 & 10000 & 1.21 \\
\hline & 44 & 89 & 89 & 14000 & 1.28 \\
\hline \multirow[t]{4}{*}{$\mathrm{BSt}$} & 6 & 29 & 27 & 7700 & 1.18 \\
\hline & 12 & 55 & 56 & 13000 & 1.19 \\
\hline & 18 & 68 & 68 & 16000 & 1.18 \\
\hline & 28 & 80 & 89 & 19000 & 1.14 \\
\hline
\end{tabular}

${ }^{\mathrm{a}} \mathrm{St} /$ Comonomer $=1(\mathrm{~mol} / \mathrm{mol}) .[\mathrm{MTEMPO}]_{0}=0.204 \mathrm{~mol} \mathrm{~L}^{-1}$, $[\mathrm{BPO}]_{0}=0.173 \mathrm{~mol} \mathrm{~L}^{-1}$. ${ }^{\mathrm{b}}$ Estimated by GC. ${ }^{\mathrm{c}}$ Estimated by GPC based on polystyrene standards.

Conversions of styrene were lower than those of MSt, and were even lower than those of BSt. TEMPOmediated polymerization retains the same order of reactivities of 4-substituted styrenes as that in free radical polymerization, although the polymerization rate is quite different. ${ }^{17,23,27}$ Molecular weight and polydispersity were determined by GPC calibrated with polystyrene standards. Polydispersities of the copolymer of BSt are narrower than those of MSt. Molecular weights of the copolymers decreased due to increasing the initial concentration of MTEMPO ([MTEMPO $]_{0}$ ). Molecular weights were in proportion to the reciprocal of [MTEMPO $]_{0}$ (Figure 1). Copolymerizations may thus proceed in accordance with a living mechanism, based on the fact that TEMPO-mediated polymerization of substituted styrene proceeds in a living radical manner. The copolymerizations surely proceed by a living mechanism, based on the relation between molecular weight and conversion. The results are summarized in Table II. Conversions of MSt and BSt increased over time in the same proportion as that of styrene. As shown in Figures 2 and $3, \ln [\mathrm{M}]_{\mathrm{o}} /[\mathrm{M}]$ linearly increased over time, and molecular weights were proportional to the conversions. Copolymerizations thus proceed in accordance with a living mechanism.

Figure 4 shows a ${ }^{1} \mathrm{H}$ NMR spectrum of the copolymer of styrene and MSt $\left(M_{n}=4400, M_{w} / M_{n}=1.33\right)$, obtained by polymerization for $6 \mathrm{~h}$ at $125^{\circ} \mathrm{C}$. It is clear that the copolymer has benzoyl and MTEMPO moieties, because signals of these groups are discerned in the a)

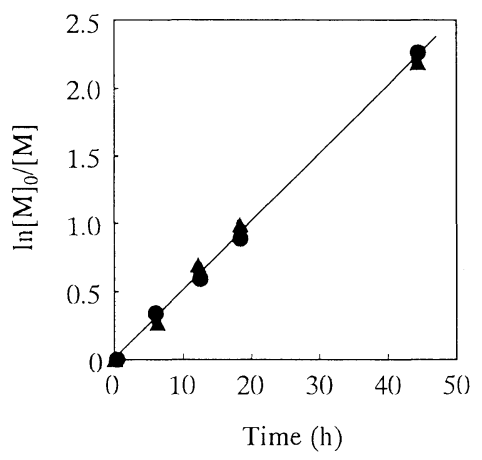

b)

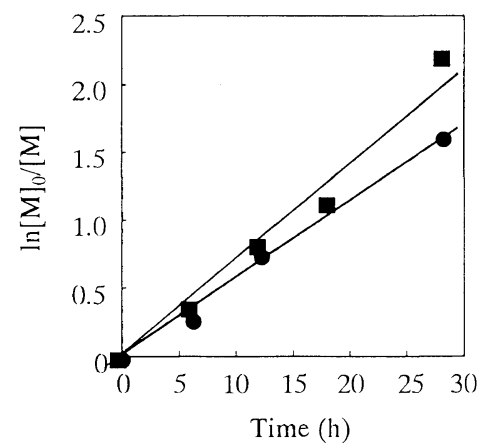

Figure 2. First order time-conversion plots in copolymerization (a) of St $(\boldsymbol{O})$ with MSt $(\boldsymbol{\Delta})$, and in copolymerization (b) of St $(\boldsymbol{O})$ with BSt ( $\square$ ) by BPO and MTEMPO.

a)

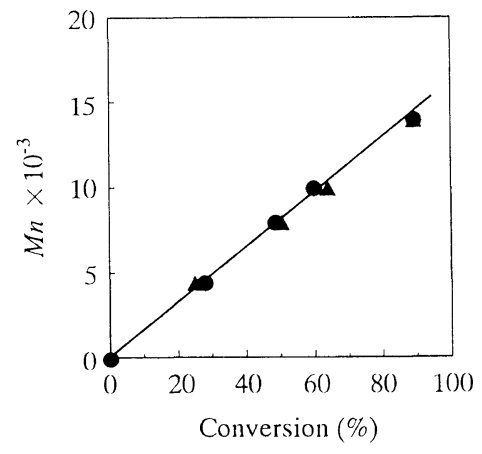

b)

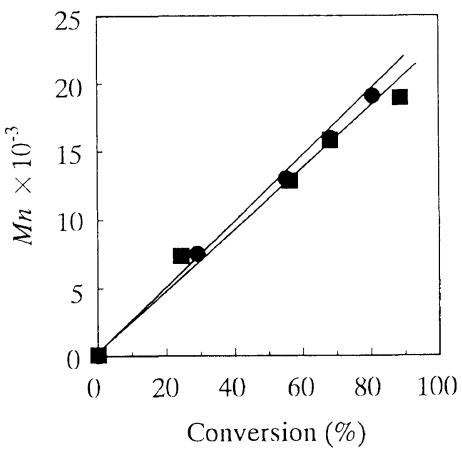

Figure 3. Plots of molecular weight versus conversion in copolymerization (a) of St ( $)$ with MSt $(\boldsymbol{\Delta})$, and in copolymerization (b) of St (๑) with BSt ( $\boldsymbol{\square})$ by BPO and MTEMPO.

spectrum. Signals at $7.86,7.51$, and $7.39 \mathrm{ppm}$ were assigned to aromatic protons at ortho, para, and meta positions of the benzoyl group, respectively. Signals originating from MTEMPO are observed at 1.12, 0.95, 0.40 , and $0.24 \mathrm{ppm}$, attributed to tetramethyl protons. 


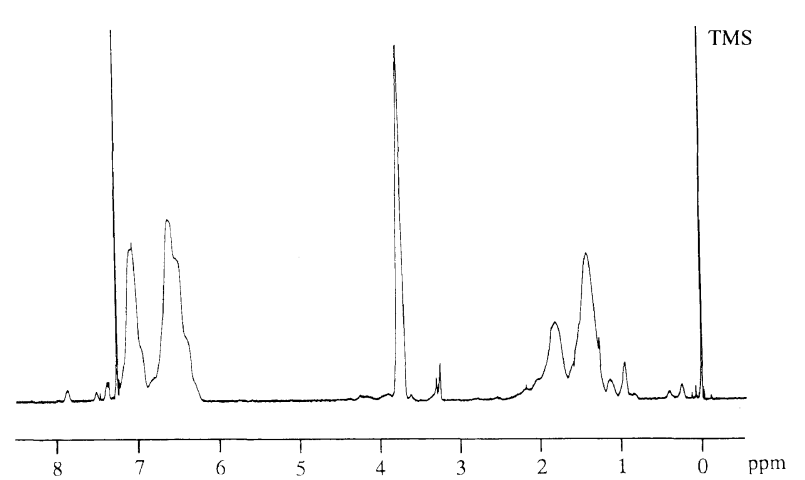

Figure 4. ${ }^{1} \mathrm{H}$ NMR spectrum of the poly(St-ran-MSt) (conversions of $\mathrm{St}=28 \%$ and of $\mathrm{MSt}=26 \%, M_{n}=4400, M_{w} / M_{n}=1.33$ ) obtained by radical polymerization of St and MSt by BPO and MTEMPO Polymerization was carried out at $125^{\circ} \mathrm{C}$ for $6 \mathrm{~h}$, after being held at $95^{\circ} \mathrm{C}$ for $3.5 \mathrm{~h}$ (solvent: $\mathrm{CDCl}_{3}$ ).

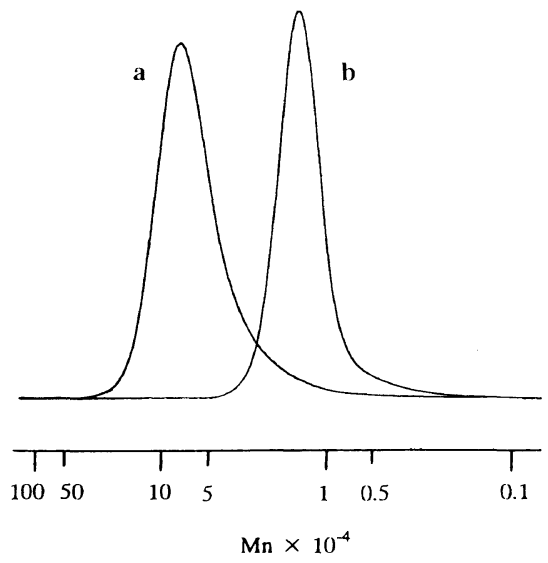

Figure 5. GPC profiles of the random block copolymer (a, $\left.M_{n}=59000, M_{w} / M_{n}=1.28\right)$ obtained by random block copolymerization of St and MSt using poly(St-ran-BSt) (b, St/BSt $=0.495 / 0.505$, $M_{n}=13000, M_{w} / M_{n}=1.19$ ) as an initiator (solvent: $\mathrm{CDCl}_{3}$ ).

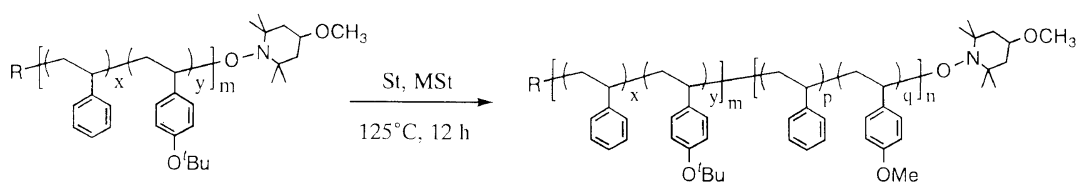

Scheme 2.

Table III. Random block copolymerization of St with MSt and with BSt by random copolymers Obtained

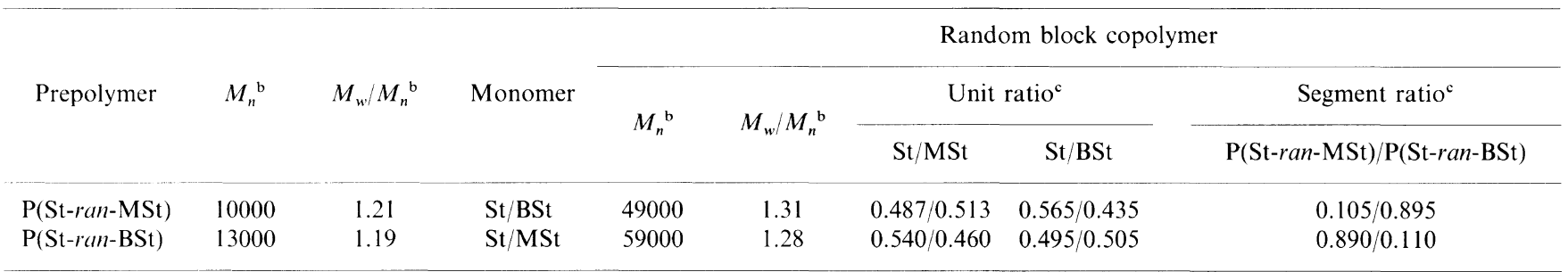

${ }^{\text {a }}$ Polymerized for $12 \mathrm{~h}$. St $/$ Comonomer $=1(\mathrm{~mol} / \mathrm{mol}) .{ }^{\mathrm{b}}$ Estimated by GPC based on polystyrene standards. ${ }^{\mathrm{c}}$ Estimated by ${ }^{1} \mathrm{H}$ NMR.

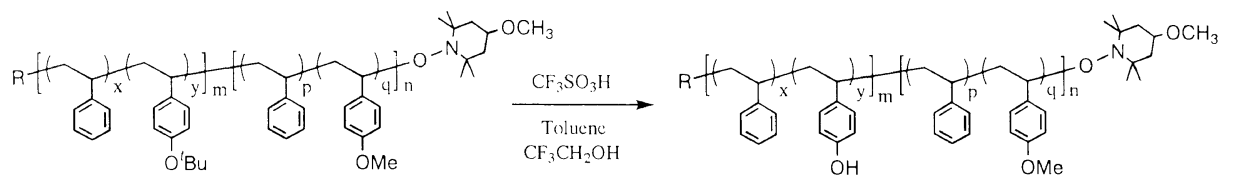

Scheme 3.

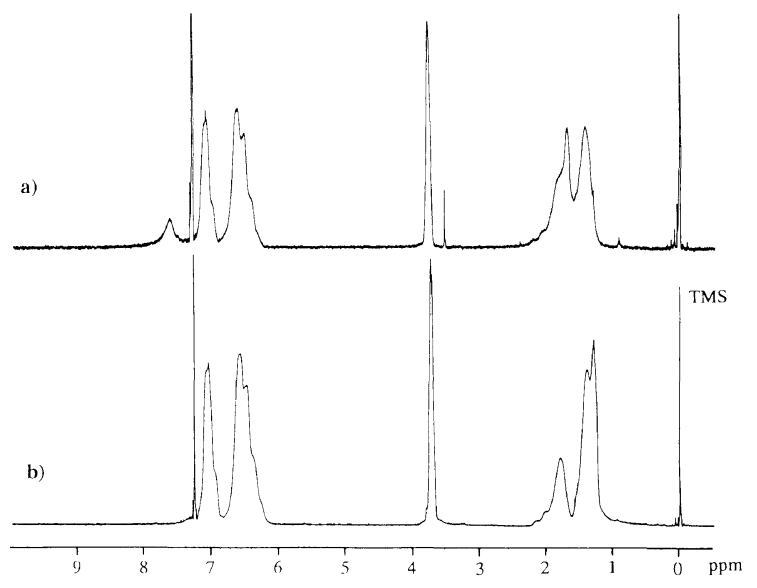

Figure 6. ${ }^{1} \mathrm{H}$ NMR spectra of the random block copolymer before (b) and after (a) hydrolysis. This copolymer was obtained by random block copolymerization of St and MSt $\left(M_{n}=59000, M_{w} / M_{n}=1.28\right)$ using poly(St-ran-BSt) $\left(\mathrm{St} / \mathrm{BSt}=0.495 / 0.505, M_{n}=13000, M_{w} / M_{n}=\right.$ 1.19 ) as an initiator (solvent: $\mathrm{CDCl}_{3}$ ).
The signals at $3.27 \mathrm{ppm}$ are also based on MTEMPO, and assigned to the methoxy protons. The ratio of MTEMPO to the benzoyl group in the copolymer is equal to that of MTEMPO to BPO used in the copolymerization, based on previous results. ${ }^{16,39}$ These ratios were closely in agreement: the former was 1.21 , estimated using the integral intensity of the signals at 7.86 and $3.27 \mathrm{ppm}$, and the later, 1.18 . The unit ratio of St to MSt in the copolymer was equal to their conversion ratio. The unit ratio was estimated to be 0.988 , and conversion ratio, 0.929 . The same results were obtained for BSt, using the copolymer with molecular weight of 7700. Random copolymers with molecular weights controlled and with unit ratios desired were attained.

The copolymers obtained could initiate random block copolymerization of St with comonomers in quantitative efficiency, since the copolymerizations proceed in accordance with a living mechanism. Block copolymerization was carried out at $125^{\circ} \mathrm{C}$ for $12 \mathrm{~h}$ (Scheme 2). 


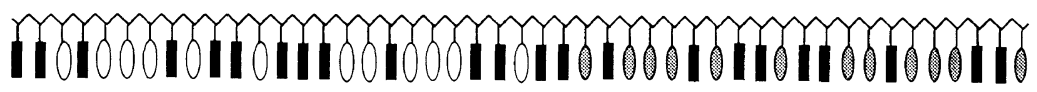

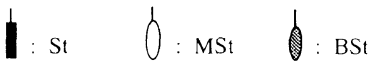

Scheme 4.

The results are listed in Table III. Poly(St-ran-MSt) initiated the copolymerization of St with BSt, giving a block copolymer comprising poly(St-ran-MSt) and poly(St-ran-BSt), and vice versa. Quantitative formation of these block copolymers was attained, based on GPC analysis. Figure 5 shows GPC profiles of the block copolymer obtained from poly(St-ran-BSt) and of the prepolymer. The block copolymer showed unimodal GPC, and the peak of the prepolymer was hardly observed in GPC of the resulting copolymer. The synthesis of well-defined random block copolymers comprising poly(St-ran-MSt) and poly(St-ran-BSt) should thus be possible by living radical polymerization using MTEMPO. The random copolymers obtained in high conversions were used as initiators for block copolymerization, giving random block copolymers without quantitative efficiency. This is based on the fact that the peak of prepolymer partly remained, after the block copolymerization. This implies that decomposition based on disproportionation of the growing chain end is involved in a latter stage of polymerization.

The $t$-butoxy groups of BSt can be hydrolyzed to phenolic hydroxy moieties without any harm to methoxy moieties of MSt units. Hydrolysis of the block copolymers obtained was performed at $-5^{\circ} \mathrm{C}$ in a mixture of toluene and trifluoroethanol by trifluoromethanesulfonic acid as a catalyst (Scheme 3 ). The block copolymer obtained from the prepolymer of poly(St-ran-MSt) was hydrolyzed to a polymer which dissolved neither in water nor in organic solvents. The block copolymer produced from poly(St-ran-BSt) gave an insoluble polymer. This product swelled in chloroform. Figure 6 shows ${ }^{1} \mathrm{H}$ NMR spectra of this block copolymer before and after hydrolysis. In the spectrum of the resulting polymer, no observation of a signal was made at $1.30 \mathrm{ppm}$ due to the $t$-butoxy groups. The reaction did no harm to MSt units because there was no change of ratio of the methoxy protons of MSt to the aromatic ones. The sharp signal at $1.70 \mathrm{ppm}$ originated from water remaining in the resulting polymer, based on the fact that the signal was shifted to low magnetic field side by the addition of $\mathrm{CF}_{3} \mathrm{COOH}$. These results indicate that $t$-butoxy groups in the copolymer are selectively hydrolyzed to hydroxy groups, with the result of formation of a random block copolymer including vinyl phenol units.

\section{CONCLUSIONS}

The synthesis of random block copolymers comprising poly(St-ran-MSt) and poly(St-ran-BSt) was attained by the radical polymerization using MTEMPO. The polymerization of St with MSt and with BSt proceeded in accordance with a living mechanism, giving random copolymers with molecular weights controlled and the desired monomer unit ratios. The random copolymers obtained efficiently initiated block copolymerization to give block copolymers consisting of two different random copolymers. BSt units were selectively hydrolyzed to vinyl phenol ones, with formation of a random block copolymer comprising poly(St-ran-vinyl phenol) and poly(St-ran-MSt). These random block copolymers had unique structures where comonomers "indirectly" formed a block copolymer in a matrix of styrene units (Scheme 4). The copolymers should show different properties and behavior from those based on blends of the respective random copolymers and of their simple block copolymers. This is because the matrix of styrene units disturbs or weakens interaction between the respective copolymer units. Such random block copolymers may be useful for creating novel unique materials.

\section{REFERENCES}

1. R. P. Quirk, J. Yin, and L. J. Fetters, Macromolecules, 22, 85 (1989).

2. K. Ueda, A. Hirao, and S. Nakahama, Macromolecules, 23, 939 (1990).

3. K. Takenaka, A. Hirao, and S. Nakahama, Macromol. Chem. Phys., 196, 1687 (1995).

4. Ph. Dubois, R. Jerome, and Ph. Teyssie, Polym. Bull., 22, 475 (1989).

5. S. Kohjiya, T. Ohtsuki, S. Yamashita, M. Taniguchi, and T. Hashimoto, Bull. Chem. Soc. Jpn., 63, 2089 (1990).

6. I. Goodman, Ed., "Development in Block Copolymers, 1," Applied Science Publishers, London, 1982.

7. P. Rempp, P. Luts, P. Masson, and E. Franta, Makromol. Chem. Suppl., 8, 3 (1984)

8. A. Deffieux, M. Schppacher, and L. Rique-Lubet, Polymer, 35, 4562 (1994).

9. Y. Tezuka and E. J. Goethals, Makromol. Chem., 188, 791 (1987).

10. R. P. N. Veregin, M. K. Georges, P. M. Kazmaier, and G. K. Hamer, Macromolecules, 26, 5316 (1993).

11. G. Moad and E. Rizzardo, Macromolecules, 28, 8722 (1995).

12. R. P. N. Veregin, P. G. Odell, L. M. Michalak, and M. K. Georges, Macromolecules, 29, 3346 (1996).

13. T. Fukuda, T. Terauchi, A. Goto, K. Ohno, Y. Tsujii, and T. Miyamoto, Macromolecules, 29, 6393 (1996).

14. K. Ohno, Y. Tsujii, and T. Fukuda, Macromolecules, 30, 2503 (1997).

15. R. P. N. Veregin, M. K. Georges, G. K. Hamer, and P. M. Kazmaier, Macromolecules, 28, 4391 (1995).

16. E. Yoshida and Y. Okada, J. Polym. Sci., Polym. Chem., 34, 3631 (1996).

17. E, Yoshida and T. Fujii, J. Polym. Sci., Polym. Chem. Ed., 36, 269 (1998).

18. K. Matyjaszewski, T. Shigemoto, J. Frechet, and M. Leduc, Macromolecules, 29, 4167 (1996).

19. C. J. Hawker, Angew. Chem. Int. Ed. Engl., 34, 1456 (1995).

20. C. J. Hawker and J. L. Hedrick, Macromolecules, 28, 2993 (1995).

21. E. Yoshida and Y. Okada, Bull. Chem. Soc. Jpn., 70, 275 (1997).

22. E. Yoshida and S. Tanimoto, Macromolecules, 30, 4018 (1997).

23. E. Yoshida, J. Polym. Sci., Polym. Chem., 34, 2937 (1996).

24. P. M. Kazmaier, K. Daimon, M. K. Georges, G. K. Hamer, and R. P. N. Veregin, Macromolecules, 30, 2228 (1997).

25. C. J. Hawker, E. Elce, J. Dao, W. Volksen, T. P. Russell, and G. G. Barclay, Macromolecules, 29, 2686 (1996).

26. T. Fukuda, T. Terauchi, A. Goto, Y. Tsujii, and T. Miyamoto, Macromolecules, 29, 3050 (1996).

27. E, Yoshida and T. Fujii, J. Polym. Sci., Polym. Chem. Ed., 35, 2371 (1997). 
28. C. J. Hawker, J. Am. Chem. Soc., 116, 11185 (1994).

29. E. Yoshida and A. Sugita, Macromolecules, 29, 6422 (1996).

30. E. Yoshida and A. Sugita, J. Polym. Sci., Polym. Chem., 36, 2059 (1998).

31. E. Yoshida and Y. Osagawa, Macromolecules, 31, 1446 (1998).

32. E. Yoshida and M. Nakamura, Polym. J., 30, 915 (1998).

33. D. Greszta and K. Matyjaszewski, Polym. Prepr. Am. Chem. Soc., 37, 569 (1996)

34. Y. Kotani, M. Kamigaito, and M. Sawamoto, Polym. Prepr. Jpn.,
46, 1536 (1997)

35. J. Qiu and K. Matyjaszewski, Acta Polym., 48, 169 (1997).

36. K. Ohno, Y. Tsujii, T. Fukuda, T. Miyamoto, Polym. Prepr., Jpn., 46, 1524 (1997).

37. T. Miyazawa, T. Endo, S. Shiihashi, and M. Okawara, J. Org. Chem., 50, 1332.

38. L. J. Young, J. Polym. Sci., 54, 411 (1961).

39. R. P. N. Veregin, P. G. Odell, L. M. Michalak, and M. K. Georges, Macromolecules, 29, 2746 (1996). 